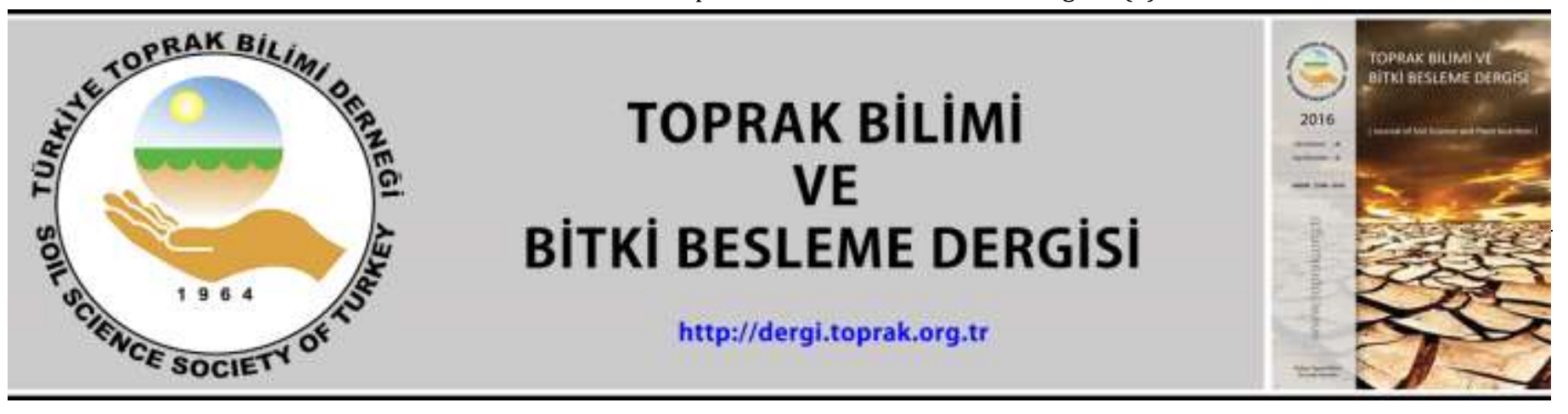

\title{
Vejetasyon indis değerleri ile şeker pancarı yaprak azot içeriğinin izlenmesi
}

\section{Mert Dedeoğlu *}

\author{
Selçuk Üniversitesi, Ziraat Fakültesi, Toprak Bilimi ve Bitki Besleme Bölümü, Konya
}

\section{Özet}

Yaprak azot $(\mathrm{N})$ içeriği fotosentez ve bitki metabolizmasındaki kritik rolleri nedeniyle tarımsal uygulamalar için en önemli değişkenlerdendir. Bu çalışmada Sentinel 2A uydu görüntülerinden türetilen Redge -NDVI değerleri ile üç farklı vejetasyon dönemi için şeker pancarı bitkisinde yaprak \%N içeriklerinin parsel bazlı olarak ilișkilendirilmesi amaçlanmıștır. Çalıșma Konya-Çumra bölgesinde seçilen 26 farklı çiftçi arazisinden Mayıs-Haziran-Temmuz 2019 tarihlerinde alınan yaprak örnekleri ve belirtilen tarihlere yakın temin edilen uydu görüntüleri kullanılarak yürütülmüştür. Araştırma ile vejetatif gelişim ve kök oluşum evresinde yaprak \%N içerikleri ve Redge - NDVI değerleri arasında tatmin edici doğruluk katsayıları $\left(0.74 \leq \mathrm{r}^{2} \leq 0.83\right)$ elde edilmiş, ancak şeker pancarı kök büyüme dönemi içerisinde ilişkinin azaldığı $\left(\mathrm{r}^{2}<0.70\right)$ belirlenmiştir. Çalışma sonucu şeker pancarı bitkisinin erken-orta vejetasyon dönemlerinde \%N içeriğinin hızlı ve tahribatsız olarak geniş alanlarda ve kısa zaman aralıklarında izlenmesi için Sentinel 2A uydu görüntüsü ve Red Edge spektral bandının kullanımı başarılı bulunmuştur. Ayrıca benzer araştırmaların yürütülmesi ile azot kullanım etkinliğini artırabilir uzaktan algılama uygulamalarına değerli bilgiler sağlanabileceği önerilmiştir. Anahtar Kelimeler: Azot, red edge bant, Sentinel-2, șeker pancarı, vejetasyon indisi.

\section{Monitoring of leaf nitrogen content in sugar beet by vegetation index values}

\begin{abstract}
Leaf nitrogen $(\mathrm{N})$ content is one of the most important variables for agricultural applications due to its critical roles in photosynthesis and plant metabolism. In this study, it was aimed to relate the Redge -NDVI values derived from Sentinel $2 \mathrm{~A}$ satellite images with the leaf $\mathrm{N} \%$ contents in sugar beet plants for three different vegetation periods on a parcel basis. The study was carried out using leaf samples taken from 26 different farmers' lands selected in Konya-Çumra region between May-June-July 2019 and satellite images provided close to the specified dates. With the research, satisfactory accuracy coefficients $\left(0.74 \leq \mathrm{r}^{2} \leq 0.83\right)$ were obtained between leaf $\mathrm{N}$ contents and Redge - NDVI values during the vegetative and root development phase, but it was determined that the relationship decreased $\left(\mathrm{r}^{2}<0.70\right)$ during the sugar beet root growth period. As a result of the study, it was found successful to use Sentinel 2A satellite image and Red Edge spectral band in order to monitoring \% of sugar beet in early mid vegetation periods rapidly and non-destructively in large areas and short time intervals. In addition, it has been suggested that by conducting similar studies can be provided valuable information to remote sensing applications that may increase the efficiency of nitrogen.
\end{abstract}

Keywords: Nitrogen, red edge band, Sentinel-2, sugar beet, vegetation index.

(C) 2020 Türkiye Toprak Bilimi Derneği. Her Hakkı Saklıdır

\section{Giriş}

Azot yüksek kaliteli ve optimum bitki verimi için gerekli biyokimyasal reaksiyonlarda anahtar rol oynayan, üreticiler için de en yüksek gübre girdisini oluşturan bir bitki besin elementidir. Nitekim Ülkemiz bitkisel üretiminde son on yılda ortalama 7.3 milyon ton azotlu gübre kullanılmış olup bu sayı toplam gübre girdisinin \%66'sını oluşturmaktadır (Anonim, 2020). Azotun hem fizyolojik hem de ekonomik olarak bitkisel yetiştiricilikte bu denli önemli olması bitkilerin vejetasyon dönemleri boyunca yaprak azot içeriklerinin periyodik olarak takip edilmesini gerektirmektedir (Zhao ve ark., 2019). Uzaktan algılama teknikleri bu konuda tahribatsız ve pratik bir yaklaşım sunmaktadır. Geçmişten günümüze bitki yeşil aksamı üzerine kurgulanan uzaktan algılama ve yansıma spektroskopisi araştırmaları öncelikle $\mathrm{N}$ içeriğini tahmin etmek ve izlemek üzerine odaklanmıştır (Guo ve ark., 2016). Uzaktan algılama tekniklerinin geniş alanlarda uygulanmasına olanak sağlayan en yaygın kullanım şekli ise çok bantlı (multispectral) ve yüksek

\section{* Sorumlu yazar:}

Tel. : : 05304160006

E-posta : mdedeoglu@selcuk.edu.tr
Geliș Tarihi

Kabul Tarihi
19 Nisan 2020

24 Haziran 2020
e-ISSN

DOI : $10.33409 /$ tbbbd.757448 
çözünürlüklü (High-spectral resolution) uydu görüntülerinden elde edilen spektral yansıma ölçümleridir (Jackson, 1986; Shou ve ark, 2007; Jia ve ark., 2011). Sivil yer gözlem uyduları ile elektromanyetik spektrumun farklı dalga boylarında (bant aralıklarında) elde edilen spektral yansımalar, özellikle bitkilerin kimyasal kompozisyonlarını belirlemek amacıyla ERTS-1 (Landsat-1) uydusunun uzaya firlatıldığı 1972 yılından bu yana araştırılmaktadır. Bugün Türkiye'nin de dâhil olduğu pek çok ülke sahip oldukları 596 sivil yer gözlem uyduları ile günümüz gelişen bilim ve teknolojisiyle eş güdümlü olarak tarımsal amaçlı uzaktan algılama çalışmalarında önemli aşamalar kaydetmiştir. Bu çalışmaların başında farklı bitki stres koşullarının erken dönemde belirlenebilirliğine yönelik uygulamalar gelmektedir (Başayiğit ve ark, 2017; Maimaitiyiming ve ark, 2017). Yapılan çalışmalar bitkilerin kimyasal kompozisyonları ile bitki yeşil aksamından farklı dalga boylarında elde edilen spektral yansımaların (spektral imza) matematiksel olarak ilişkilendirilmesine dayanmaktadır (Li ve ark., 2008; Başayiğit ve ark, 2017). Bitkilere ait spektral yansıma değerlerinden stres koşullarının etkilerini belirlemek amacıyla kullanılan en yararlı dalga boyları ise kırmızı (Red), kızıl kenar (Red-Edge $=680-760 \mathrm{~nm}$ ) ve yakın kızılötesi (NIR) spektrum aralığıdır (Min ve Lee, 2005). Nitekim Quickbird uydu görüntüsünün Yeșil (590 nm) - Yakın kızılötesi (880 nm) bant aralıklarında mısır bitkisinin azot içeriğinin tahmin edilebildiği ve yakın kızılötesi bant yansıma oranlarının azot içeriği ile yüksek korelasyon gösterdiği belirtilmiştir (Bausch ve Khosla, 2010). Ancak günümüzde çok bantlı ve yüksek çözünürlüklü uydu görüntüleri ile yapılan çalışmalarda NDVI (Normaliz Different Vegetation Index) başta olmak üzere tüm yeşil bitkilerin biyofiziksel özellikleri birimsiz radyometrik ölçümler olarak tanımlanan vejetasyon indisleri (Effective Leaf Area Index, Green Normalized Difference Vegetation Index, Healthy-Index, Leaf Area Index, Damage Sensitive Spectral Index vb.) ile karakterize edilebilir olmasına rağmen, kimyasal içerilerini belirlemeye yönelik indisler bitki türü / stres faktörü kombinasyonları ile sınırlı kalmaktadır (Fitzgerald ve ark., 2010; Bagheri ve ark., 2011; Wójtowicz ve ark., 2016). Bu nedenle araştırmalar bitkilerde doğrudan besin elementi seviyelerinin belirlenmesine yönelik model/indis geliştirme çalışmaları yerine, özellikle stratejik bitki türlerine ait uydu görüntülerinden elde edilen kanopy (yeşil alan) yansıma değerlerinin farklı vejetasyon indisleri ile ilişkilendirerek anahtar besin elementlerinin izlenmesine yönelmektedir (Mee ve ark., 2017). Bu amaçla Birleşik Devletler de NASA Yeryüzü Gözlemleri Ticarileştirme ve Uygulama Programları (NASA's Earth Observations Commercialization and Applications Program) dâhilinde yürütülen çalışmada, mısır bitkisinde faklı dozda azot uygulamaları Landsat 5 (TM) uydu görüntüsünün yeşil / yakın kızı̈ötesi (480- 550- $670 \mathrm{~nm}$ ) dalgaboyu yansımaları kullanılarak klorofil içeriğine bağlı olarak incelenmiş ve mısır bitkisinde azot tahmini için Triangular Greenness Index (TGI) modelinin kullanılabilir olduğu belirtilmiştir. Ayrıca gelişen spektral algılayıcı teknolojileri ve farklı indis uygulamaları sayesinde tarımsal alanlarda N içeriğinin belirlenmesinin Kjeldahl ve Dumas laboratuvar analiz metotlarına göre daha az maliyetli ve kısa süreli olacağı rapor edilmiştir (Hunt ve ark, 2013). Benzer şekilde, ASTER uydu görüntüsüne ait spektral yansımalar ile mısır parsellerine ait $\mathrm{N}$ içerikleri doğrusal $\left(\mathrm{r}^{2}=0.721\right)$, logaritmik $\left(r^{2}=0.710\right)$, ikinci dereceden polinominal $\left(r^{2}=0.747\right)$ ve üstel regresyon $\left(r^{2}=0.727\right)$ modelleri ile karşılaştırılmış ve kırmızı $(630-690 \mathrm{~nm})$ - yakın kızılötesi $(760-860 \mathrm{~nm})$ dalga boylarının belli matematiksel sabitler kullanılarak oranlanması sonucu mısır bitkisinin azot durumunun tahmin edilebildiği belirtilmiştir (Bagheri ve ark., 2012). Araştırmalar aynı zamanda farklı spektral algılayıcılar ile ölçülen yansıma değerlerinin tahmin yeteneklerini karşılaştırmakta ve birbirlerine olan üstünlükleri ortaya konulmaktadır. $\mathrm{Bu}$ amaçla IKONOS uydu görüntüsüne ait yansıma değerleri ile Spodmetre yansıma ölçümleri karşılaștırılmıştır. IKONOS uydu görüntüsünün Mavi (460 nm) - Kırmızı (660 nm) bant yansıma oranları NDVI, GNDVI, RVI ve OSAVI vejetasyon indisleri ile ilişkilendirilmiş ve kışlık buğday bitkisinin azot içeriğinin SPOD okumalarına göre OSAVI kullanılarak \% 73.5 daha doğru tahmin edilebildiği bildirilmiştir (Jia ve ark., 2011). Farklı uydu sensörlerinin N besin elementini tahmin etme yeteneklerinin karşılaştırıldığı benzer bir çalışma sonucu WorldView-2 uydusunun sahip olduğu ekstra bantlardan (Coastal, Red - Edge, NIR-2) ötürü FORMASAT-2 uydusuna göre daha üstün ve kullanılabilir olduğu bildirilmiştir (Huang ve ark., 2017). Uydu görüntüleri ile yürütülen araștırmalar sonucu elde edilen bulgular, yeni nesil uydu platformlarının benzer çalışmaların doğruluklarını arttıracak şekilde dizayn edilmesini ve algılayıcı sensör yeteneklerinin arttırılmasını sağlamıştır (Mee ve ark., 2017). Bu gelişmeler sonucu WorldView - 2 uydu görüntüsünden elde edilen yansıma oranları ile pirinç bitkisinin N içeriğinin tahmini çalışılmıştır. Kontrollü şartlarda yetiştirilen ve farklı dozlarda besin elementi uygulanan pirinç bitkisinin N içeriği 8 bantta spektral algılama yapabilen WorldView - 2 uydu görüntüsünden türetilen yansıma oranları ile stepwise çoklu doğrusal regresyon $(S M L R=0.82)$ ve kısmi en küçük kareler regresyon (PLSR $=0.83$ ) analizlerinden üretilen modeller ile tahmin edilmiștir. Çalıșma sonucu WorldView - 2 uydu platformunun kızl-kenar (Reg Edge: 629-688 nm) ve yakın kızıötesi - 1 (NIR-1: 772- 890) bandının N içeriğinin tahmininde en anlamlı spectral imzaları verdiği rapor edilmiştir. (Huang ve ark., 2017). Ancak araştırmalarda besin elementi içerik 
konsantrasyonlarının izlenmesinde farklı ekolojilerde ve bitki türlerinde daha fazla çalışmalar yürütülmesi gerekliliği ortaya konulmaktadır (Haboudane ve ark., 2008; Fitzgerald ve ark., 2010; Mee ve ark., 2017; Huang ve ark., 2017). Özellikle yüksek azot ihtiyacı duyan ve gıda güvenliği açısından stratejik konumda olan bitkileri için azot durumunun izlenmesi gelişmiş ve gelişmekte olan ülkeler için büyük öneme sahiptir. Bu çalışma ile Ülkemiz ve Konya ovası için stratejik ve sosyolojik öneme sahip şeker pancarı (Beta vulgaris) bitkisinin optimum gelişiminde anahtar rol oynayan ve en yüksek kimyasal gübre girdisine sahip Azot $(\mathrm{N})$ besin elementi durumunun Sentinel 2A uydu görüntüsünden türetilecek Redge - NDVI değerleri ile izlenmesi ve yer gerçekleri ile ilişkisi araştırılmıştır.

\section{Materyal ve Yöntem}

\section{Çalışma alanının genel özellikleri}

Çalışma Konya ili Çumra ilçesinde 995 ha büyüklüğündeki test alanında seçilen 26 farklı şeker pancarı tarlasında yürütülmüştür (Şekil 1). Çumra ilçesi Konya Kapalı Havzası'nın bitkisel yetiştiricilik yapılan çukur bölgesini temsil etmekte olup, bölgede gübre ve su ihtiyacı yüksek şeker pancarı, mısır ve ayçiçeği yetiştiriciliği yoğun bir şekilde yapılmaktadır. Bölge fizyografik olarak homojen ve düz alüvyal ova

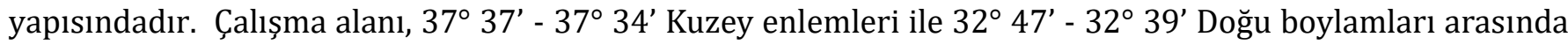
yer almaktadır (Şekil 1). Araştırma sahasının deniz seviyesinden yüksekliği 1010 m'dir. Bölgede yıllık ortalama yağıș miktarı $296.8 \mathrm{~mm}$, yıllık sıcaklık ortalaması $11.4{ }^{\circ} \mathrm{C}$, yıllık buharlaşma miktarı ise 996.60 mm'dir (Anonim, 2018).

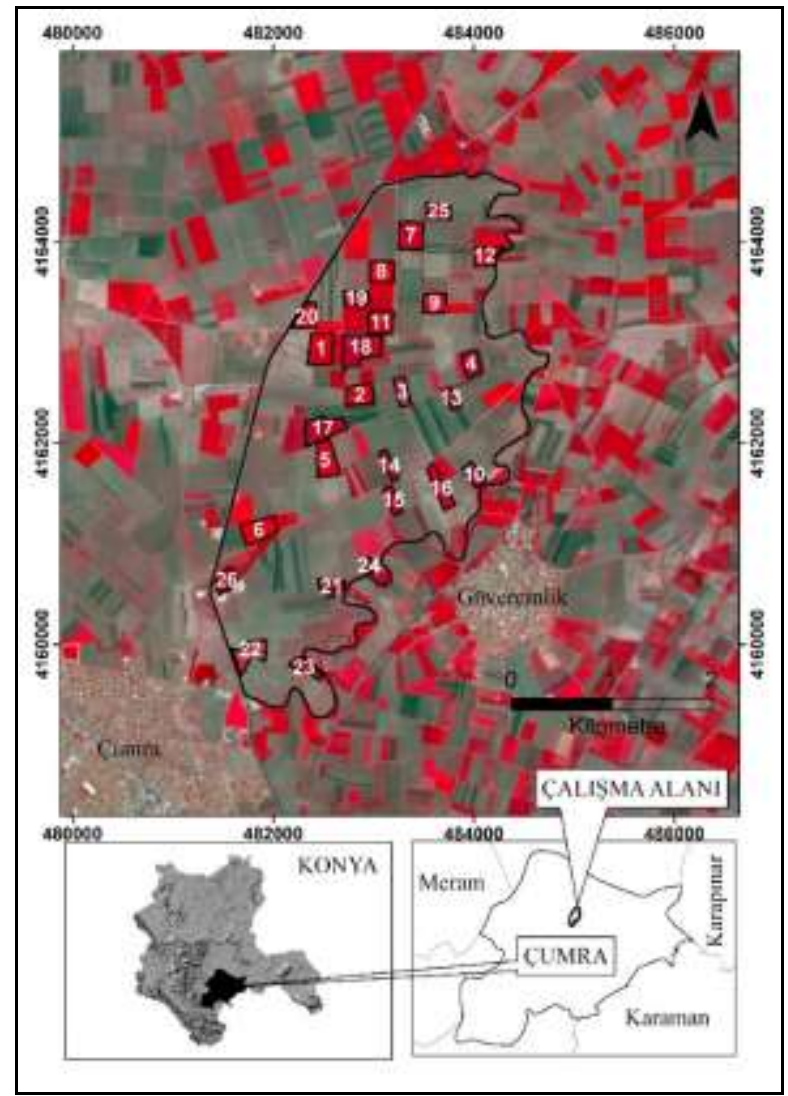

Şekil 1. Çalışma alanı Yer Buldur Haritası ve Örnek Parselleri

\section{Parsel seçimi, yaprak örneklemesi ve laboratuvar analizleri}

Konya - Çumra bölgesinde pancar yetiştiriciliği yapılan 26 farklı parsel yaprak örneklemesi ve Sentinel 2A uydu görüntülerinden indis değerleri türetimi için seçilmiştir. Parsel büyüklüklerinin $10.000 \mathrm{~m}^{2}$ ve üzerinde olmasına dikkat edilmiştir. $10.000 \mathrm{~m}^{2}$ büyüklügü̈nde bir parselde $15 \mathrm{~cm}$ sıra üstü, $45 \mathrm{~cm}$ sıra arası ekimi yapılan pancar bitkisinden yaklaşık olarak 150.000 adet bulunmakta olup (Anonim, 2012), bu rakam Sentinel 2A uydu verisinden türetilecek $20 \mathrm{~m}$ çözünürlüğe sahip indis görüntüsünde çalışmanın yürütülmesi için uygun yeterliliktedir (Huang ve ark, 2017). Yaprak örneklemeleri şeker pancarı bitkisinin vejetasyon süresi içerisinde çimlenme ve çıkışın tamamlanmasını müteakip vejetatif gelişme, kök oluşumu ve kök büyüme dönemlerinde olmak üzere 3 farklı zamanda yapılmıştır. Konya bölgesinde şeker pancarının çimlenme ve çıkış dönemi 15 Nisan - 15 Mayıs tarihlerini kapsamaktadır (Anonim, 2012). İlk örnekleme vejetatif gelişme dönemi içerisine rastlayan 18 Mayıs tarihinde yapılmıştır. 15 Haziran - 20 Temmuz 
tarihleri kök oluşumu dönemi olup, 20 Haziran ve 20 Temmuz tarihlerinde örneklemeler yapılmıștır. Homojen alanlardan grid yöntemi ile araziyi temsil edecek şekilde 50-75, tarla içinde farklılık belirlenen yerlerde ise 100-150 adet yaprak örneği alınmış ve toplam 1890 örnekte araştırma yürütülmüştür. Örneklemede bitkinin ortasında bulunan tamamen açılmış ve olgunlaşmasını yeni tamamlamış yapraklar saplarıyla birlikte toplanarak alınmıştır. Pancar yaprakları örnek poşetlerine koyulup analizler için soğutucu dolap içerisinde laboratuvara götürülmüştür. Laboratuvara getirilen yaprak örnekleri saplarından ayrılmış ve daha sonra yıkanmış, $70^{\circ} C^{\prime}$ de hava sirkülasyonlu kurutma dolabında kurutulmuştur. Kuruyan örnekler ögütüldükten sonra yaklaşık $0.2 \mathrm{~g}$ tartılarak kalay kaplara konulmuş ve $950^{\circ} \mathrm{C}$ 'de isıtılan helyum, oksijen ve kuru hava ile çalışan LECO CN-2000 (LECO Corp.) cihazında Dumas (Wright ve Bailey, 2001) metoduyla azot miktarları tespit edilmiştir.

\section{Uydu görüntülerinin temini ve indis uygulaması}

Araştırmada Avrupa Uzay Ajansı (ESA) sunucularından (https://scihub.copernicus.eu/) ücretsiz olarak temin edilebilen 26 Mayıs, 27 Haziran, 26 Temmuz 2019 tarihli Sentinel 2 Level -2A uydu görüntüleri kullanılmıştır. Belirtilen tarihler arazi çalışmalarına en yakın zaman aralıklarını temsil eden, bulut kapama oranı düşük ve geometrik distilasyonu en uygun görüntüler olarak seçilmiştir. Sentinel - 2A (1) bir haftadan daha kısa bir zamansal çözünürlüğe, (2) 10 m ile 60 arasında değişen çok bantlı uzamsal çözünürlüğe ve (3) tarımsal izleme araştırmalarında güvenilir çıkarımlar sunan kırmızı ve kırmızı kenar spektrum bölgelerinde dar bantlara sahip yeni nesil uzaktan algılama platformudur (Pasqualotto ve ark., 2019). Aynı zamanda atmosfer altı yansıtım (Top-Of-Atmosphere) değerlerini içeren Level-2A görüntüleri, geometrik ve atmosferik düzeltmeleri yapılmış olarak sunulmaktadır (Drusch ve ark. 2012). Sentinel 2 uydu görüntüsü bant özellikleri Çizelge 1' de sunulmuştur.

Çizelge 1. Sentinel 2A sensörü spektral bantları ve özellikleri

\begin{tabular}{ccccc}
\hline Bant & Function & Dalgaboyu $(\mathrm{nm})$ & Bant genişliği (nm) & Uzamsal Çözünürlük (m) \\
\hline 1 & Aerosol & 443 & 27 & 60 \\
2 & Blue & 490 & 98 & 10 \\
3 & Green & 560 & 45 & 10 \\
4 & Red & 665 & 38 & 10 \\
5 & Vegetation red-edge & 705 & 19 & 20 \\
6 & Vegetation red-edge & 740 & 18 & 20 \\
7 & Vegetation red-edge & 783 & 28 & 20 \\
8 & Near infrared (NIR) & 842 & 145 & 10 \\
$8 \mathrm{a}$ & Vegetation red-edge & 865 & 33 & 20 \\
9 & Water vapor & 945 & 26 & 60 \\
10 & SWIR & 1380 & 75 & 60 \\
11 & SWIR & 1610 & 143 & 20 \\
12 & SWIR & 2190 & 242 & 20 \\
\hline
\end{tabular}

Çalışmada şeker pancarı yapraklarının \%N içeriğinin 3 farklı dönemde Sentine $2 \mathrm{~A}$ uydu görüntüsü ile takip edilebilirliğinin belirlenmesi amacıyla Red Edge Normalize Edilmiş Fark Bitki Örtüsü İndeksi (Redge - NDVI) kullanılmıştır (Fernández-Manso ve ark., 2016). NDVI geçmişte yürütülen pek çok araştırmada farklı bitki türlerinin zamansal olarak değişebilen \%N içeriklerinin tahmininde (Cabrera-Bosquet ve ark., 2011), yeşil aksam yoğunluğunun belirlenmesinde (Verhulst ve ark., 2009), bitki gelişiminin izlenmesi (Mezera ve ark., 2017), verim tahminlerinde (Lambert ve ark., 2018) ve bitki örtüsü sınıflama araştırmalarında yaygın kullanıma sahip, güvenilir bir algoritmadır. NDVI ile genellikle kırmızı ve yakın kızı̈ötesi yansıma değerlerine bağlı hesaplamalara dayalı değerlendirmeler yapılmıș olup son yıllarda kırmızı bant yerine kızıl kenar bant (Red Edge) kullanımı ile daha tatmin edici sonuçlar elde edildiği bildirilmiştir (Zhao ve ark., 2019). Bu nedenle Redge - NDVI kullanımı çalışmanın amacına uygun bulunmuş ve şeker pancarı yaprak \%N içeriğinin takip edilmesindeki başarısı test edilmiş̧tir. Redge - NDVI eşitliği aşağıda aşağıda sunulmuştur.

Redge $-N D V I=(N I R-R E D E D G E) /(N I R+R E D E D G E)$

Sentinel 2A uydu görüntülerinden Redge - NDVI değerlerinin türetilmesinde ESA-SNAP görüntü işleme programı kullanılmıştır.

\section{Parsel indis haritalarının üretilmesi ve uzamsal istatistik analizler}

Araştırmada test parsellerinin ortalama Redge-NDVI değerleri ArcGIS 9.3 (ESRI, 2010), programının "Zonal Statistics" aracı kullanılarak hesaplanmıştır. Bu sayede her bir şeker pancarı parselini temsil eden vejetasyon indis değerleri türetilmiştir. Parsel bazlı olarak belirlenen indis değerleri ile parsel \%N içerikleri arasındaki regresyonel ilişki MS Excel programı ile belirlenmiştir. 


\section{Bulgular ve Tartışma}

Şeker pancarı parsellerinden 3 farklı dönemde alınan yaprak örneklerine ait \%N içerikleri parsel bazlı olarak Çizelge 2' de sunulmuştur.

Çizelge 2. Şeker pancarı yaprakları parsel bazlı ortalama \%N içerikleri

\begin{tabular}{|c|c|c|c|c|c|c|c|}
\hline Parsel No & $\begin{array}{c}\% \mathrm{~N} \\
\text { Temmuz }\end{array}$ & $\begin{array}{c}\% \mathrm{~N} \\
\text { Haziran }\end{array}$ & $\begin{array}{c}\% \mathrm{~N} \\
\text { Mayıs }\end{array}$ & Parsel No & $\begin{array}{c}\% \mathrm{~N} \\
\text { Temmuz }\end{array}$ & \%N Haziran & $\%$ N Mayıs \\
\hline 1 & 3.44 & 4.21 & 4.23 & 14 & 2.22 & 3.5 & 3.58 \\
\hline 2 & 2.18 & 4.1 & 4.4 & 15 & 4.23 & 4.17 & 4.35 \\
\hline 3 & 2.84 & 4.75 & 3.51 & 16 & 6.25 & 6.9 & 7.22 \\
\hline 4 & 5.36 & 7.18 & 7.5 & 17 & 6.8 & 7.8 & 7.81 \\
\hline 5 & 4.22 & 4.24 & 5.8 & 18 & 5.26 & 6.1 & 6.96 \\
\hline 6 & 4.68 & 4.85 & 4.66 & 19 & 5.2 & 5.2 & 6.32 \\
\hline 7 & 4.35 & 4.33 & 5.36 & 20 & 4.13 & 5.25 & 5.78 \\
\hline 8 & 3.12 & 3.95 & 3.92 & 21 & 4.11 & 4.3 & 4.75 \\
\hline 9 & 3.46 & 4.2 & 4.27 & 22 & 6.34 & 7.15 & 6.78 \\
\hline 10 & 5.18 & 6.1 & 6.61 & 23 & 3.27 & 4.16 & 4.83 \\
\hline 11 & 4.2 & 4.55 & 4.55 & 24 & 4.62 & 5.33 & 6.28 \\
\hline 12 & 6.15 & 6.3 & 6.76 & 25 & 3.23 & 3.82 & 5.2 \\
\hline 13 & 2.18 & 2.88 & 3.12 & 26 & 6.71 & 7.25 & 7.33 \\
\hline
\end{tabular}

Parsellere ait ortalama \% $\mathrm{N}$ içeriklerine göre en yüksek değer Mayıs ayında \%7.81 olarak belirlenmiş olup en düşük değer \% 2.18 ile Temmuz ayı sonunda elde edilmiştir. Ortalamalar arası farklar incelendiğinde (Şekil 2) şeker pancarı vejetasyon süresi ilerledikçe yapraklarda \%N içeriğinin azalma eğiliminde olduğu gözlemlenmektedir.

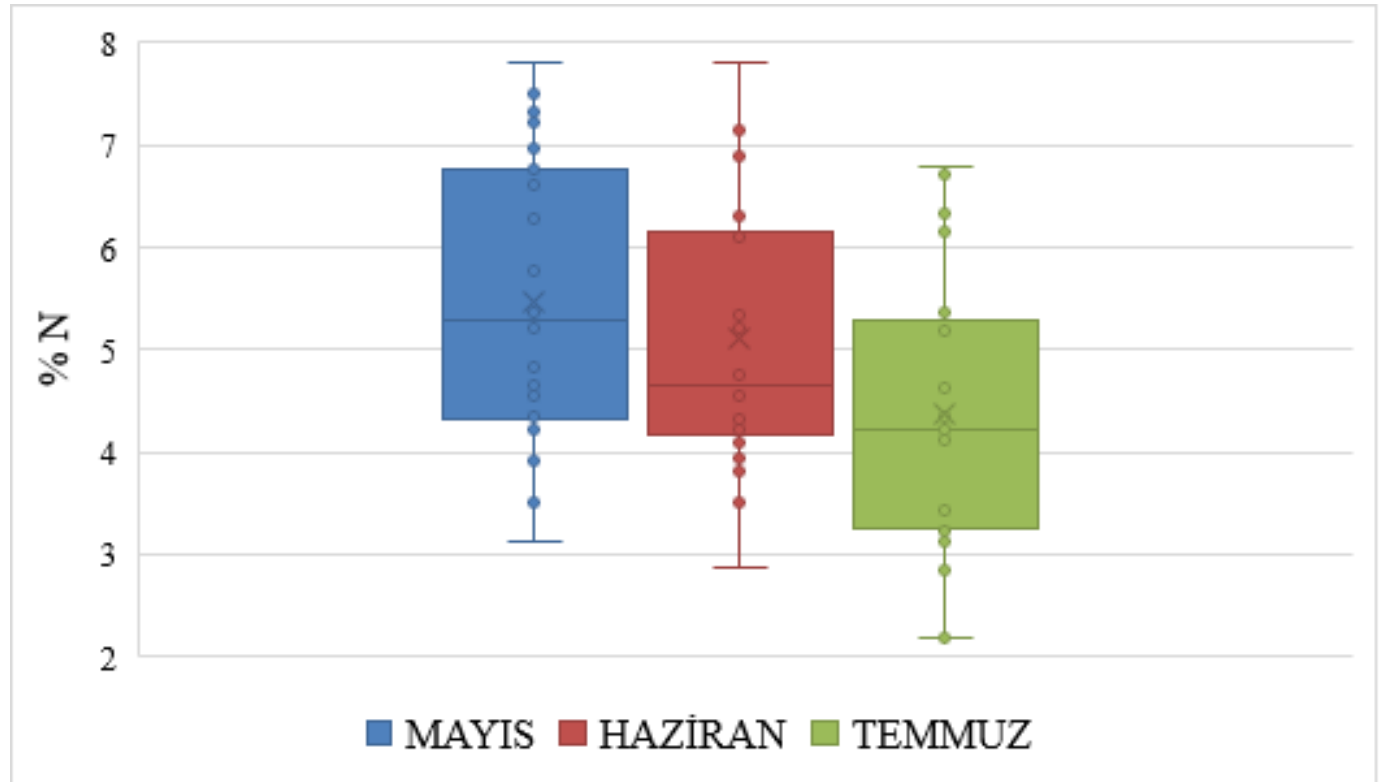

Şekil 2. Olgunlaşmasını tamamlamış şeker pancarı yapraklarının dönemsel \%N içeriği değişimi

Nitekim şeker pancarı bitkisinin kök büyüme ve olgunlaşma dönemlerine doğru bitki üst aksamındaki azotun kök bölgesine doğru taşınımı ilerlemekte ve artan kuru madde birikimine bağlı olarak $\mathrm{N}$ konsantrasyonu azalmaktadır (Gezgin ve ark., 1999). Ancak hem bölge topraklarının azot kapsamı hem de yetiştirme periyodu içerisinde yapılan gübrelemeler sonucu şeker pancarı yaprak örneklerinin \% $\mathrm{N}$ içerikleri tüm vejetasyon dönemleri için Jones ve ark., (1991)'e göre değerlendirildiğinde \%80'i yeter ve fazla sınıflarında dağılım göstermektedir. Bu durum șeker pancarı spektral yansımalarına da etki etmektedir. Öyle ki test parsellerinin \%70 inde ortalama indis değerleri 0.80-0.99 arasında dağılım göstermektedir. Test alanına ait Sentinel 2A uydu görüntülerinden 3 farklı dönemde türetilen Redge-NDVI dağılım haritaları, indis değerlerinin \%N içerikleri ile regresyonel ilişkilerine ait grafikler ve doğruluk katsayılar $\left(\mathrm{r}^{2}\right)$ Şekil 3' te sunulmuştur. 

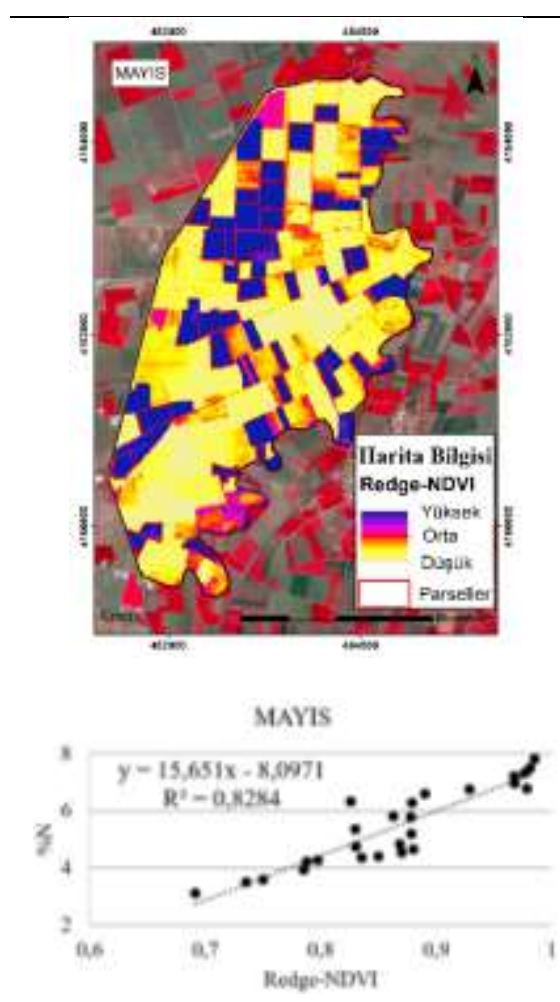
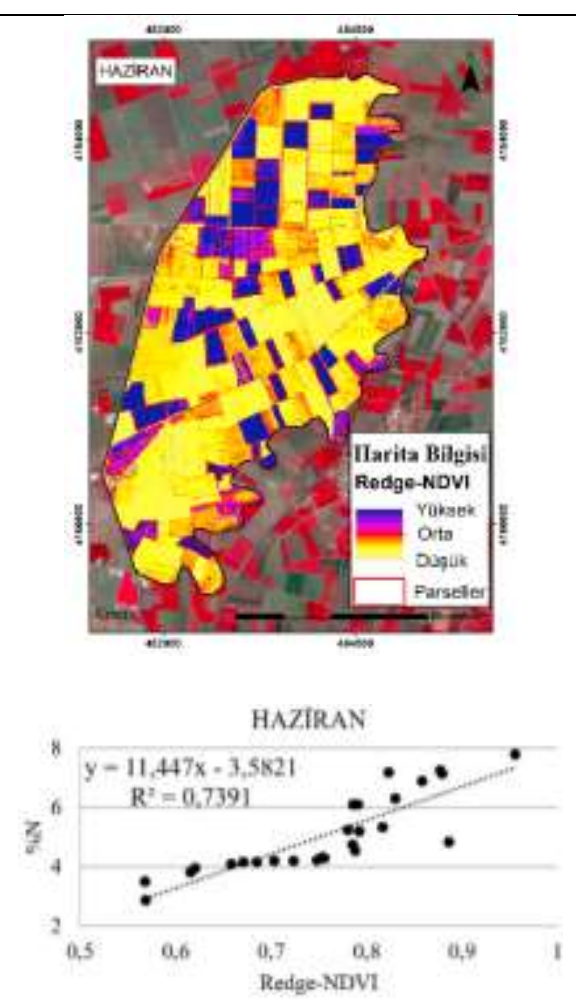
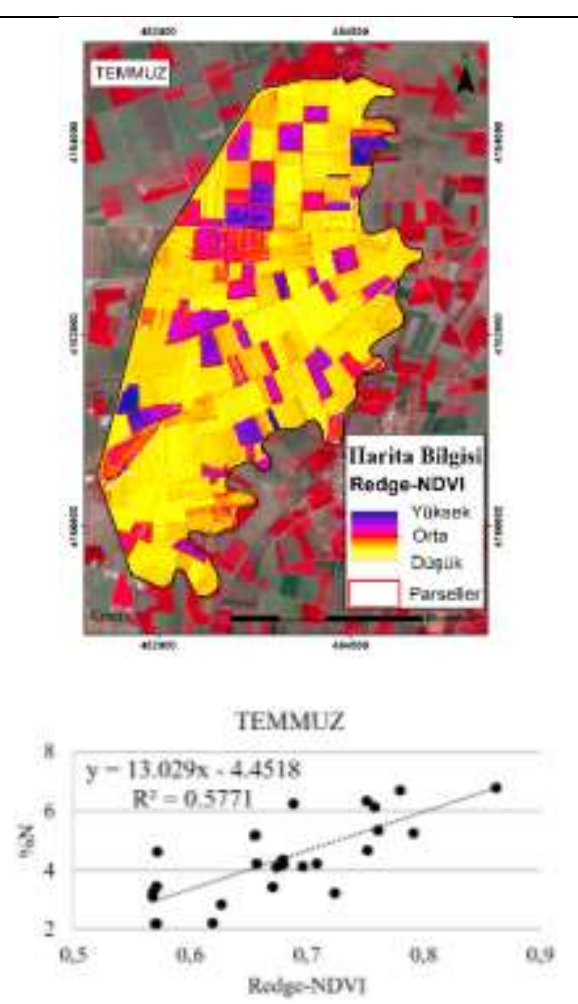

Şekil 3. Şeker pancarı parsellerine ait Redge - NDVI dağılım haritaları ve \%N içeriği ilişkisi

Parsel bazlı olarak ilişkilendirilen Redge-NDVI değerlerinin şeker pancarı \%N içeriklerini vejetatif gelişme dönemi ve kök oluşumu içerisinde yüksek doğrulukla temsil ettiği $\left(0.74 \leq r^{2} \leq 0.83\right)$ ve bitkilerin azot durumunun izlenmesinde İç Anadolu bölgesi için Mayıs ayı sonu ve Haziran ayı Sentinel 2A uydu görüntülerinin güvenilir sonuçlar verdiği belirlenmiştir. Nitekim bu dönem içerisinde şeker pancarı yaprakları olgunlaşma periyodunda olup, yaşlı yapraklar henüz gelişmemiş ya da çok az sayıdadır (Faberio ve ark., 2003). Bu durum Mayıs-Haziran aylarında tarla koșullarında örneklenen yaprakların aynı zamanda parsel yaprak popülasyonunu da temsil ettiğini göstermekte ve olgunlaşma evresindeki bu yaprakların uydu görüntülerinde baskın yeşil aksam yasıma karakteristiği sergilediği anlaşılmaktadır. Aynı zamanda şeker pancarı vejetasyon gelişim periyodu için elde edilen bulgular Red edge bandının NDVI algoritmasına fonksiyonlanmasının başarılı bir yaklaşım olduğunu da göstermektedir. Öyle ki Red edge dalgaboyu tabanlı vejetasyon indisleri veya spektral algoritmalar yaprak alanı farklılıklarına dayalı ölçümler yerine klorofil miktarı ve dolayısıyla azot içeriği ile yüksek oranda ilişkili olan yaprak rengine bağlı yansıma farklılıklarını ölçmekte (Gitelson ve Merzlyak, 1997; Sharma ve ark., 2015), böylece bitkilerin erken gelişim evrelerinde alt toprak yansımasından daha az etkilenerek faydalı yeșil aksam yansıma çıkarımları yapabildiği bilinmektedir (Clevers ve Gitelson, 2013). Sentinel 2 uydu görüntülerinin sahip olduğu red edge bant dalga boyları kullanılarak yürütülen araştırmalar da bu durumu desteklemektedir. Zhao ve ark., (2019), buğday bitkisinde $\mathrm{N}$ durumunun izlenmesinde Sentinel-2A görüntülerinden türetilen vejetasyon indisleri kullanılarak $\mathrm{r}^{2}>0.70$ doğruluk kat sayılı modeller geliștirildiği bildirilmiștir. Clevers ve ark., (2017), patates bitkisinin yaprak klorofil içeriği ile Sentinel 2 verisinden hesaplanan TCARI/OSAVI değerleri arasında $r^{2}=0.70$ ilişki olduğu ve 10-20 m uzamsal çözünürlüğe sahip spektral bantların tahmin çalışmalarında kullanımının uygun olduğu belirtilmiştir. Ancak çalışmamızda Temmuz ayı sonların da başlayan kök büyüme evresinde Redge - NDVI değerlerinin şeker pancarı yaprak \%N içeriklerini düşük doğruluk katsayısı $\left(\mathrm{r}^{2}=0.58\right)$ ile temsil ettiği ve bu dönemde Sentinel 2A uydu görüntüsünden türetilecek indis değerlerinin \%N içeriğinin izlenmesinde kullanılabilir olmadığı belirlenmiştir. Kök büyüme evresi için türetilen Redge-NDVI değerleri tüm vejetasyon süreleri için en düşük indis ortalamalarını vermiştir. Bu dönem de şeker pancarı yapraklarının artan yüzey alanına bağlı olarak azalan $\mathrm{N}$ konsantrasyonları, yaşlı yaprak topluluğunun renk koyuluklarının da azalmasına neden olmaktadır. Bu nedenle şeker pancarı parsellerinin düşük ortalama indis değerleri ile temsil edildiği belirlenmiştir. Nitekim belirtilen dönem içerisinde yeni yaprakların oluşması minimum seviyededir (Draycott ve Christenson, 2003), ve çapları yüksek genişliğe erişen yaşlı yapraklar Sentinel 2A uygu görüntüsüne ait bir piksel alanı büyük çoğunlukla örtmektedir. Bu nedenle \%N içeriğinin belirlenmesi için örneklenen yeni olgunlaşmış yaprakların kök büyüme döneminde uydu sensörleri ile ölçülen yansımalara etkisi güvenilir bir şekilde değerlendirilememektedir (Zhao ve ark., 2010). 


\section{Sonuç}

Bu çalışmada şeker pancarı \%N içeriğinin yüksek çözünürlüklü uydu görüntülerinden elde edilen vejetasyon indis değerleri ile izleme ve değerlendirme potansiyeli uygulamalı olarak araştırılmıștır. Çalışmada Sentinel 2A uydu görüntülerinden türetilen Redge - NDVI değerleri ile şeker pancarı \%N içerikleri arasında parsel bazlı olarak erken - orta vejetasyon periyotları içerisinde tatmin edici ilişkiler elde edilmiş, olgunlaşma dönemi ve ilerisi için kullanım kabiliyetinin zayıfladığı belirlenmiştir. Aynı zamanda Red Edge bantının alt toprak yansıma etkisini azaltma yeteneğinden ve klorofil pigmentine hassas duyarlılığından dolayı özellikle vejetatif gelişme dönemi başlangıcında \%N içeriğinin izlenmesinde başarılı bulunmuş ve benzer fenolojik araştırmalarda Red Edge dalgaboyu (705 -740 - $783 \mathrm{~nm}$ ) yansıma aralığında ölçüm kabiliyetinden dolayı Sentinel 2A uydu görüntüleri kullanımı önerilmiştir. Geçmiş araştırmalarda uydu teknolojileri farklı bitki türleri için N içeriklerinin takip edilmesinde hızlı, tahribatsız ve geniş alanları eşzamanlı olarak tarayabilen araçlar olarak yararlı bulunmuştur. Bu çalışmada elde edilen bulgular önceki çalışmaları destekler nitelikte olup ek olarak geleneksel çiftçi uygulamaları ile yetiştirilen şeker pancarı bitkisinde yaprak \% $\mathrm{N}$ içeriklerinin Sentinel 2A görüntüleri ile izlenmesinde uygun dönemsel çıkarımlar yapılmıştır. Ancak yürütülen pek çok araştırmalarda vejetasyon indislerine dayalı azot ya da klorofil içeriği gibi bitki biyokimyasal özelliklerinin tahmin ve/veya takip edilmesinde daha yüksek veya daha düşük doğruluk katsayılı çıkarımlar yapılabilmektedir. Bu durum yansıma değerlerinin sensör yetenekleri, topak özellikleri, iklim ve atmosfer olayları, çiftçi uygulamaları, bitki zararlıları vb. pek çok faktörden etkilenmesinden ileri gelmekte olup, tarımsal amaçlı uzaktan algılama çalışmalarının da kırılgan tarafını oluşturmaktadır. Bu nedenle benzer çalışmaların farklı bitki çeşitleri ile arazi koşullarında kurulacak ve değişen azotlu gübre uygulamalarının yansımalara etkisinin araştırılacağı denemeler ile yürütülmesi önerilmiş, bu sayede hassas tarım uygulamalarının önemli bir kolu olan uzaktan algılama ile bitki fizyolojisinin izlenmesi çalışmalarına önemli katkı sağlanabileceği öngörülmüştür.

\section{Kaynaklar}

Anonim, 2012. Bitkisel üretim çiftçi rehberi, konyaseker.com.tr/Upload/Files/seker-pancari.pdf.

Anonim, 2018. Tarım ve Orman Bakanlığı Meteorolojı Genel Müdürlüğü, https://www.mgm.gov.tr/veridegerlendirme/il-ve-ilceler-istatistik.aspx (Erişim tarihi 22.06.2019)

Anonim, 2020, www.tuik.gow.tr (Erişim tarihi 16.06.2020)

Bagheri N, Ahmadi H, Alavipanah S, Omid M, 2012. Soil-line vegetation indices for corn nitrogen content prediction. International Agrophysics. 26(2): 103-108.

Başayiğit L, Dedeoğlu M, Akgül H, Uçgun K, Altındal M, 2017. Investigation of N deficiency in cherry trees using visible and near-infrared spectra part of the spectrum in field condition. Spectroscopy and Spectral Analysis.37(1): 293298.

Bausch WC, Khosla R, 2010. QuickBird satellite versus ground-based multi-spectral data for estimating nitrogen status of irrigated maize. Precision Agriculture. 11(3): 274-290.

Cabrera-Bosquet L, Molero G, Stellacci, A, Bort J, Nogues, S, Araus J, 2011. NDVI as a potential tool for predicting biomass, plant nitrogen content and growth in wheat genotypes subjected to different water and nitrogen conditions. Cereal Res. Comm. 39(1): 147-159.

Clevers JG, Kooistra L, Van den Brande MM, 2017. Using Sentinel-2 data for retrieving LAI and leaf and canopy chlorophyll content of a potato crop. Remote Sensing. 9(5): 405.

Clevers JGPW, Gitelson AA, 2013. Remote estimation of crop and grass chlorophyll and nitrogen content using red-edge bands on Sentinel-2 and -3. Int. J. Appl. Earth Obs. Geoinform 23:344-351.

Draycott AP, Christenson DR, 2003. Nutrients for sugar beet production: Soil-plant relationships. Cabi.

Drusch M, Del Bello U, Carlier S, Colin O, Fernandez V, Gascon F, Hoersch B, Isola C, Laberinti P, Martimort P, Meygret A, Spoto F, Sy O, Marchese F, Bargellini P, 2012. Sentinel-2: ESA's optical high-resolution mission for GMES operational services. Remote Sensing of Env. 120: 25-36.

Faberio C, Martin de Santa Olalla F, Lopez R, Dominguez A, 2003. Production and quality of the sugar beet cultivated under contrelled deficit irrigation conditions in a semi-arid climate. Agric. Water Manage. 62: 215-227.

Fernández-Manso A, Fernández-Manso 0, Quintano C, 2016. SENTINEL-2A red-edge spectral indices suitability for discriminating burn severity. International J. App. Earth Obs. Geo. 50: 170-175.

Fitzgerald G, Rodriguez D, O'Leary G, 2010. Measuring and predicting canopy nitrogen nutrition in wheat using a spectral index-The canopy chlorophyll content index (CCCI). Field Crops Research. 116(3): 318-324.

Gezgin S, Dursun N, Hamurcu M, Ayaslı Y, 1999. Konya ovasinda şeker pancarı bitkisinde beslenme sorunlarinin toprak ve bitki analizleri ile Belirlenmesi. Konya Pancar Ekicileri Kooperatifi Yayını, 1999, Konya.

Gitelson AA, Merzlyak MN, 1997. Remote estimation of chlorophyll content in higher plant leaves. Int. J. Remote Sens. 18: 2691-2697.

Guo BB, Qi SL, Heng YR, Duan JZ, Zhang HY, Wu YP, Feng W, Xie YX, Zhu YJ, 2016. Remotely assessing leaf N uptake in winter wheat based on canopy hyperspectral red-edge absorption. Eur. J. Agron. 82: 113-124. 
Haboudane D, Tremblay N, Miller JR, Vigneault P, 2008. Remote estimation of crop chlorophyll content using spectral indices derived from hyperspectral data. IEEE Trans. Geosci. Remote Sens. 46: 423-437.

Huang S, Miao Y, Yuan F, Gnyp M, Yao Y, Cao Q, 2017. Potential of RapidEye and WorldView-2 satellite data for improving rice nitrogen status monitoring at different growth stages. Remote Sensing. 9(3): 227.

Hunt ER, Doraiswamy PC, McMurtrey JE, Daughtry CS, Perry EM, Akhmedov B, 2013. A visible band index for remote sensing leaf chlorophyll content at the canopy scale. Int. J. App. Earth Obs. Geo. 21: 103-112.

Jackson RD, 1986. Remote sensing of biotic and abiotic plant stress. Annual Review of Phytopathology 24: 265-286.

Jia L, Yu Z, Li F, Gnyp M, Koppe W, Bareth G, Miao Y, Chen X, Zhang F, 2011. Nitrogen status estimation of winter wheat by using an Ikonos satellite image in the north china plain. Computer and computing technologis in agriculture V. 5 th IFIP TC5/SIG 5,1 Conference, CCTA 2011 Beijing, Cina, October 2011 Proceedings, Part II.

Jones JR, Wolf B, Mills HA, 1991. Plant analysis handbook, Micro Macro Publishing Inc.

Lambert M, Traoré PCS, Blaes X, Baret P, Defourny P, 2018. Estimating smallholder crops production at village level from Sentinel-2 time series in Mali's cotton belt. Remote Sensing of Environment. 216: 647-657.

Li F, Gnyp ML, Jia LL, Miao YX, Yu ZH, Koppe W, Bareth G, Chen XP, Zhang FS, 2008. Estimating N status of winter wheat using a handheld spectrometer in the North China Plain. Field Crops Res. 106: 77-85.

Maimaitiyiming M, Ghulam A, Bozzolo A, Wilkins JL, Kwasniewski MT, 2017. Early detection of plant physiological responses to different levels of water stress using reflectance spectroscopy. Remote Sensing. 9(7): 745.

Mee CY, Siva KB, Ahmad HMH, 2017. Detecting and monitoring plant nutrient stress using remote sensing approaches: A review. Asian J. Plant Sci. 16: 1-8.

Mezera J, Lukas V, Elbl J, 2017. Evaluation of crop yield spatial variability in relation to variable rate application of fertilizers. MendelNet. 24(1): 17-37.

Min M, Lee WS, 2005. Determination of significant wavelengths and prediction of nitrogen content for citrus. Transactions of the ASAE. 48(2): 455-461.

Pasqualotto N, Delegido J, Van Wittenberghe S, Rinaldi M, Moreno J. 2019. Multi-crop green LAI estimation with a new simple Sentinel-2 LAI index (SeLI). Sensors, 19(4): 904.

Sharma LK, Bu H, Denton A, Franzen DW, 2015. Active-optical sensors using red NDVI compared to red edge NDVI for prediction of corn grain yield in North Dakota, USA. Sensors. 15(11): 27832-27853.

Shou LN, Jia LL, Cui ZL, Chen XP, Zhang FS, 2007. Using high-resolution satellite image to evaluate nitrogen status of winter wheat in the North China Plain. Journal of Plant Nutrition. 30(10): 1669-1680.

Verhulst N, Govaerts B, Sayre KD, Deckers J, François IM, Dendooven L, 2009. Using NDVI and soil quality analysis to assess influence of agronomic management on within-plot spatial variability and factors limiting production. Plant and Soil. 317(1): 41-59.

Wójtowicz M, Wójtowicz A, Piekarczyk J, 2016. Application of remote sensing methods in agriculture. Comm. in Bio. and Crop Sci. 2016(11): 31-50.

Wright AF, Bailey JS, 2001. Organic carbon, total carbon, and total nitrogen determinations in soils of variable calcium carbonate contents using a Leco CN-2000 dry combustion analyzer. Comm. in Soil Sci. Plant A. 32(19-20): 32433258.

Zhao F, Gu X, Verhoef W, Wang Q, Yu T, Liu Q, Zhao H, 2010. A spectral directional reflectance model of row crops. Remote Sensing of Environment. 114(2): 265-285.

Zhao H, Song X, Yang G, Li Z, Zhang D, Feng H, 2019. Monitoring of nitrogen and grain protein content in winter wheat based on Sentinel-2A data. Remote Sensing 11(14): 1724. 